\title{
Riemer Roukema
}

\section{Geheime geschriften in het vroege christendom}

Naast de breed overgeleverde geschriften van het Nieuwe Testament en andere oudkerkelijke literatuur bestaan er ook werken die door hun auteurs als 'verborgen' ofwel 'geheim' of 'apocrief' werden genoemd. Die zijn vooral - dus niet uitsluitend - bekend geworden dankzij de vondst, eind 1945, van gnostische manuscripten in de omgeving van Nag Hammadi in Egypte. Dit artikel introduceert enkele van deze geschriften en gaat in op de vraag in hoeverre hierin betrouwbare geheime tradities over Jezus en zijn eerste leerlingen te vinden zijn.

De vroegchristelijke literatuur kan op allerlei manieren worden ingedeeld. Men denke bijvoorbeeld aan de verschillende literaire genres zoals brieven, traktaten, preken, evangeliën en visionaire openbaringen; of aan de identiteit van de auteurs, zoals christenen van joodse of niet-joodse afkomst, of van gnostische groeperingen als de Valentinianen en de zogenoemde Sethianen. Over de mogelijke categoriseringen bestaan heel verschillende opvattingen. Soms is bijvoorbeeld ontkend dat de zogenoemde gnostici christenen zijn, zelfs al was Christus voor hen belangrijk, op hun eigen manier. Zo is een brief van de Valentiniaanse gnosticus Ptolemaeus, die daarin een christelijk verstaan van de oudtestamentische wet van Mozes voorstelt, in de gezaghebbende Franse serie Sources Chrétiennes uitgegeven en vertaald onder de vermelding 'Série annexe de textes non chrétiens.' ${ }^{1}$ De gedachte hierachter was, dat alleen auteurs die stonden in de traditie van wat later de kerkelijke orthodoxie werd christen waren, zodat anderen die naar Christus verwezen als onchristelijke ketters beschouwd moesten worden.

Deze bijdrage is gewijd aan een categorie van vroegchristelijke geschriften die door hun auteurs of samenstellers expliciet worden gepresenteerd als 


\section{Roukema}

'geheim' ofwel 'verborgen'; apókryphos in het Grieks, apocrief dus. Nu geeft Van Dale's Groot woordenboek van de Nederlandse taal van 2015 onder het lemma 'apocrief' twee betekenissen: 1. 'door de kerk niet als gezaghebbend erkend', als tegenstelling van 'canoniek', ofwel 'Bijbelboeken die niet tot de canon gerekend worden', en 2. 'niet authentiek', in de zin van 'ongeloofwaardig, onaannemelijk'. In dit artikel gebruik ik de term 'apocrief' niet in deze tweede betekenis, en ook niet geheel volgens de eerste definitie. De geschriften die ik ga bespreken worden namelijk doorgaans in de tweede eeuw of in het begin van de derde eeuw gedateerd, en toen was er nog geen nauwomschreven kerkelijke canon van gezaghebbende vroegchristelijke geschriften. Weliswaar tekenden in die tijd de contouren van zo'n canon - het latere Nieuwe Testament dus - zich al wel af, maar omdat een redelijk breed geaccepteerde nieuwtestamentische canon nog niet formeel was vastgesteld, is de tegenstelling 'apocrief versus canoniek' dan nog niet aan de orde. ${ }^{2}$ Wel is voor die periode de tegenstelling 'apocrief versus in de kerk gezaghebbend' relevant, al erken ik direct dat de term 'kerk' dan ook gedefinieerd moet worden. Voor het te bestuderen tijdvak versta ik daaronder het netwerk van gemeenschappen en hun leiders die, met al hun onderlinge verschillen, uitgingen van de 'regel van het geloof' in God als de Schepper van de wereld, in zijn zoon die mens geworden is en Jezus Christus is genoemd, die voor de verlossing van de mensheid is gestorven en uit de dood opgestaan, en in de heilige Geest. ${ }^{3}$

Als een vroegchristelijke auteur of samensteller zijn geschrift expliciet apocrief ofwel 'geheim' noemde, dan deed hij dat om het te onderscheiden van andere geschriften die niet geheim waren en in het toenmalige netwerk van de kerk gezag hadden gekregen. Die andere geschriften waren onder meer de evangeliën die werden toegeschreven aan Marcus, Matteüs, Lucas en Johannes, de Handelingen der apostelen, brieven van of op naam van Paulus en andere brieven op naam van Jacobus, Petrus en Johannes. Later zijn deze alle opgenomen in het Nieuwe Testament, samen met nog andere brieven zoals die aan de Hebreeën, een brief op naam van Judas, en een Openbaring aan of van Johannes; maar het zou anachronistisch zijn de apocriefe geschriften van de tweede en begin derde eeuw al tegenover de nieuwtestamentische canon te stellen. Die canon is door verschillende bisschoppen en synodes voorgesteld dan wel vastgesteld in de vierde tot zesde eeuw, maar ook daarna namen 'kerkelijke' ofwel katholieke christenen nog vaak genoeg kennis van geschriften die daarin niet waren opgenomen. ${ }^{4}$

De geschriften die ik hier ga introduceren omdat hun auteurs ze expliciet 
als 'apocrief' of 'verborgen' aanduiden, zijn het Evangelie van Thomas, het Boek van Thomas, het Geheime boek van Jacobus, het Geheime boek van Johannes en het Evangelie van Judas. Al deze werken zijn overgeleverd in het Koptisch (een late vorm van het oude Egyptisch), en hoogstwaarschijnlijk zijn ze alle vertaald uit het Grieks. Alleen van het Evangelie van Thomas zijn ook Griekse fragmenten teruggevonden, maar uitgerekend van dit werk veronderstellen sommige geleerden dat het oorspronkelijk in het Syrisch is geschreven. De meeste van deze Koptische teksten maken deel uit van de collectie van gnostische handschriften die eind 1945 in de omgeving van de Egyptische stad Nag Hammadi is teruggevonden en tussen 1959 en 1989 is gepubliceerd en vertaald. ${ }^{5}$ Het Evangelie van Judas maakt deel uit van een andere, kleinere gnostische collectie die pas in 2006 is gepubliceerd. Naast deze vijf geheime geschriften zijn er nog enkele tientallen andere werken die hiermee nauw verwant zijn. Omdat van sommige van deze overige geschriften het opschrift verloren gegaan of zwaar beschadigd is, is het mogelijk dat ook daar oorspronkelijk een term als apocrief of geheim heeft gestaan. Dit betreft bijvoorbeeld het Evangelie van Maria en de Openbaring van Paulus.

\section{Het Evangelie van Thomas}

Dat het Evangelie van Thomas op naam van deze leerling van Jezus staat, betekent niet dat het ook echt door hem is geschreven of samengesteld. ${ }^{6}$ Het bevat 114 spreuken en korte gesprekken waarin Jezus aan het woord is. Sommige spreuken wijken slechts weinig af van de versies die in de eerste drie nieuwtestamentische evangeliën staan. Zo geheim waren althans die spreuken dus niet, ondanks de aankondiging in het opschrift: 'Dit zijn de verborgen woorden die Jezus de Levende heeft gesproken en die Didymus Judas Thomas heeft opgeschreven.' Voor 'verborgen' staat er het Koptische woord ethêp, dat hoogstwaarschijnlijk een vertaling is van de Griekse term apókryphoi. Volgens dit evangelie (13) heeft alleen Thomas Jezus echt begrepen, anders dan diens andere leerlingen. De collectie begint met de belofte dat wie de uitleg van deze woorden vindt, niet zal sterven. Dit betekent dat zo iemand in geestelijke zin het ware leven zal vinden. Daarop volgt Jezus' aansporing dat de lezer niet moet ophouden te zoeken (d.w.z. naar die uitleg, ofwel de diepere betekenis van dit evangelie) totdat hij vindt. Jezus onthult dat het Koninkrijk (nl. van God) niet alleen iets uiterlijks is dat buiten zijn volgelingen te vinden zou zijn, maar dat het zich in hun binnenste bevindt, en dat ze in dat opzicht tot zelfkennis moeten komen (1-3). Te 


\section{Roukema}

midden van de spreuken die sterk verwant zijn met Jezus' onderricht in de nieuwtestamentische evangeliën vallen de passages die hiervan afwijken het meest op. Daarin leren Jezus' leerlingen dat zij uit het (goddelijke) licht, ofwel het Koninkrijk, afkomstig zijn en dat ze ertoe bestemd zijn daarnaar terug te keren. Daartoe zijn ze uitverkoren door God, de Levende Vader (49-50). Om dat Koninkrijk te bereiken en het tijdens het leven op aarde al in zichzelf te ontdekken, dienen ze afstand te nemen van de wereld (27). Een andere voorwaarde is dat ze het mannelijke en het vrouwelijke in zichzelf verenigen (22). Dit brengt met zich mee dat zij 'één' of 'eenlingen' worden $(4,16,23$, $49,75,106)$, ofwel celibatair leven.

Terwijl de aansporing tot zelfkennis breed in de Griekse wereld voorkwam, is het ideaal om innerlijk één te worden specifiek Platonisch. Dat de zielen uit het licht afkomstig zijn, is eveneens bij Plato te vinden. ${ }^{7}$ Aan het eind van dit evangelie zegt Jezus dat hij zijn leerlinge Maria (Magdalena) mannelijk zal maken zodat ook zij een levende geest wordt. ${ }^{8} \mathrm{Hij}$ besluit: 'Want iedere vrouw die zich mannelijk maakt zal het Koninkrijk der hemelen binnengaan' (114). Hiermee lijkt hij mannen voor te trekken, maar in feite sluit deze spreuk aan bij de destijds gangbare associatie van het mannelijke met het geestelijke, en het vrouwelijke met het fysieke en aardse. Bovendien wordt - zoals hierboven al bleek - van mannen verwacht dat zij op hun beurt het vrouwelijke in zichzelf integreren. ${ }^{9}$

\section{Het Boek van Thomas}

Veel minder bekend dan het Evangelie van Thomas is het Boek van Thomas dat eveneens in de collectie van Nag Hammadi staat. Volgens het opschrift bevat het de 'verborgen (ethêp) woorden' die de Verlosser - Jezus - sprak tot Judas Thomas en die door Mathaias zijn opgetekend; ${ }^{10}$ deze informatie zal echter niet echt op deze personen teruggaan. Het boek is gesitueerd na Jezus' opstanding uit de dood en voordat hij in de hemel werd opgenomen. Jezus noemt Thomas zijn tweelingbroer (in het Hebreeuws en Aramees betekent deze naam 'tweeling') en zegt hem dat hij kennis, inclusief zelfkennis heeft verworven. Jezus keert zich scherp tegen allen die verlangen naar seks. Hij houdt Thomas voor dat wie de waarheid zoekt, op vleugels wegvliegt van die verterende hartstocht. Hij kondigt aan dat, wanneer Thomas dit onderricht gaat uitdragen en mensen het dan versmaden, zij zullen worden overgeleverd aan de Heerser van deze wereld, die hen in de Tartarus zal werpen. Jezus spreekt elf verwensingen uit over hen die in hun dwaling geheel op hun eigen

\section{8}


lichaam zijn gericht en drie zaligsprekingen over hen die de verzoekingen weerstaan en daarom door anderen worden bespot en verdrukt.

Ook volgens dit Boek van Thomas behelsde de geheime leer van Jezus dus een consequent celibatair leven en zelfs een afkeer van seks. Met de 'Heerser van deze wereld' is de God bedoeld die volgens het Oude Testament de wereld heeft geschapen. Hij krijgt hier duivelse trekken. ${ }^{11}$

\section{Het Geheime boek van Jacobus}

Ook het Geheime boek van Jacobus is te vinden in de handschriften van Nag Hammadi. ${ }^{12}$ In de Koptische tekst wordt dit geschrift aangeduid met het Griekse leenwoord apokryphon. Het Koptisch bevat zeer veel Griekse leenwoorden, dus het gebruik van een Griekse term is niet vreemd. Ongetwijfeld was dit woord apokryphon ook in het Griekse origineel te vinden. De auteur stelt zich voor als Jacobus, met wie hoogstwaarschijnlijk de broer van Jezus is bedoeld die de leiding over de eerste christelijke gemeente te Jeruzalem kreeg. ${ }^{13}$ Geleerden nemen echter niet aan dat deze Jacobus echt de auteur van dit geschrift is.

Jacobus beschrijft dat Jezus, de Verlosser, 550 dagen na zijn opstanding uit de dood aan zijn twaalf leerlingen verscheen en toen Jacobus en Petrus apart nam om hen in te wijden in zijn onderricht. Opmerkelijk is dat Jezus hun zegt dat alleen degenen die geloven in zijn kruis verlost zullen worden, en dat het Koninkrijk van God aan zulke gelovigen toekomt. Die nadruk op het geloof in Jezus Christus als de gekruisigde Verlosser komt in andere gnostische geschriften amper voor, en soms wordt daarin zelfs nadrukkelijk ontkend dat hij, als hemelse gestalte, echt gekruisigd is. In dit werk op naam van Jacobus zegt Jezus: 'Denk aan mijn kruis en aan mijn dood, en jullie zullen leven.' Zijn onderricht typeert Jezus met vier termen: geloof, liefde en daden, waaruit het leven voortkomt; met dat leven is het ware, verloste leven bedoeld. Even daarna zegt Jezus bovendien dat zij het hemelse Koninkrijk alleen kunnen vinden door kennis; hiervoor gebruikt de Koptische tekst het Griekse leenwoord gnôsis. De inhoud van die gnôsis wordt niet toegelicht, maar we mogen aannemen dat die is te vinden in de woorden van Jezus die in dit geschrift zijn opgetekend. Na diverse verwensingen van wie niet in hem hebben geloofd en zaligsprekingen tot hen die hem wel echt hebben leren kennen, ging de hemel open en werd Jezus daarin opgenomen. Daar bekleedde hij zich met een hemels lichaam. Tot slot stuurde Jacobus de apostelen elk naar een eigen plaats (om daar Jezus' boodschap bekend te 


\section{Roukema}

maken) en ging hij zelf naar Jeruzalem.

\section{Het Geheime boek van Johannes}

Het Geheime boek van Johannes is in vier Koptische handschriften bewaard gebleven, waarvan drie voorkomen in de collectie van Nag Hammadi en één in de Berlijnse Gnostische Codex. Het is op naam van Jezus' leerling Johannes overgeleverd in een kortere en een langere versie; ${ }^{14}$ niemand neemt echter aan dat dit werk echt van hem stamt. ${ }^{15}$ In het onderschrift van de vier manuscripten wordt ook dit geschrift apokryphon genoemd. Johannes vertelt hierin hoe hij, na Jezus' terugkeer naar zijn oorsprong, een visioen kreeg van de bovenhemelse Vader, Moeder en Zoon. Een man - Christus - verklaart wie zij zijn, hoewel de Vader in wezen onkenbaar is. Ook andere bovenhemelse machten worden voorgesteld, onder wie Sophia, die eigenmachtig en tot haar latere verdriet het gedrocht Jaldabaoth voortbracht. Met de heersers en engelen die uit hem voortkwamen schiep deze de wereld, ook de mens, Adam, maar diens 'psychische lichaam' was aanvankelijk levenloos. Jaldabaoth blies hem toen de geest in die hij van zijn moeder Sophia had ontvangen, en zo werd de mens een 'lichtwezen' dat een groter inzicht had dan de scheppende machten. Uit jaloezie wierpen zij hem daarom uit hun hemelsfeer op aarde, waar hij een materieel, sterfelijk lichaam ontving. In het paradijs zette de Verlosser - Christus - hem aan tot het eten van de boom van kennis van goed en kwaad, hetgeen de toorn van Jaldabaoth opriep. Hij wilde het inzicht, dat in Adam schuilging, tijdens diens slaap uit hem verwijderen, maar toen dat gebeurd was herkende Adam het als het Leven (Zôê, de Griekse vertaling van de Hebreeuwse naam Eva). Jaldabaoth vervloekte daarop de aarde en verwekte bij Eva de zonen Eloim en Jawe (twee Hebreeuwse namen van God in het Oude Testament), alias Kaïn en Abel. Adam verwekte bij Eva hun zoon Seth, 'het beeld van de zoon van de mens'. Seth is het prototype van de gnostici, die op de wereld zijn om de verlossing van de mensen te dienen door hun met de ware gnôsis bekend te maken. ${ }^{16}$ Toen Christus, na nog andere uiteenzettingen, uit Johannes' ogen verdween, vertelde deze hiervan aan zijn medeleerlingen.

Dit visioen bevat een kritische gnostische hervertelling van de eerste vier hoofdstukken van het Bijbelboek Genesis. Hiermee distantieerde de auteur zich van de 'kerk', de christelijke hoofdstroom van zijn tijd, die deze hoofdstukken heel anders verklaarde. Vooral de gnostische visie dat de Schepper van de wereld een lagere godheid was, die was voortgekomen uit 
een eigenwijze daad van Sophia en die geen benul van de ware Vader had, impliceerde een scherpe afwijzing van het geloof in God de Schepper, dat in de kerk werd aangehangen.

\section{Het Evangelie van Judas}

Het Evangelie van Judas staat, helaas sterk gehavend, in een Koptisch handschrift, Codex Tchacos genaamd, met drie andere gnostische geschriften. ${ }^{17}$ Het begin van het opschrift luidt: 'Het verborgen (ethêp) verslag van het oordeel waarover Jezus met Judas Iskariot sprak. ${ }^{18}$ Wat volgt, speelt zich kort voor Jezus' laatste viering van het joodse Paasfeest af. Jezus bespot zijn leerlingen omdat zij de verkeerde God vereren en denken Jezus te kennen. Judas zou echter als enige hebben begrepen waar Jezus vandaan kwam en wie hij was. Het onbegrip tussen Jezus' twaalf leerlingen en hun meester komt herhaaldelijk in dit geschrift terug, en Judas steekt als dertiende gunstig bij hen af. Toch is Jezus ook kritisch over Judas, omdat hij zich door zijn ster zou hebben laten misleiden. Na allerlei onderricht van Jezus dat verwant is met het Geheime Boek van Johannes verdwijnt Jezus (in zijn geestelijke gestalte) tenslotte in een lichtwolk, en levert Judas Jezus als aardse gestalte uit aan de joodse Schriftgeleerden, die hem hiervoor betalen. Hiervan had Jezus gezegd dat Judas de mens die hem droeg (d.w.z. Jezus' lichaam) zou offeren, kennelijk aan de joodse god Saklas, wiens naam 'dwaas' betekent. Hiermee eindigt dit 'verborgen verslag', waarin ook Judas er uiteindelijk niet gunstig op staat.

Het fragmentarisch overgeleverde verhaal is een kritisch-alternatieve versie van hetgeen in de oudere kerkelijke evangeliën staat, namelijk dat Judas, een van Jezus' twaalf leerlingen, zijn meester uitlevert aan de joodse religieuze leiders die hem wilden laten ombrengen. ${ }^{19}$ Blijkens allerlei zinspelingen op die weergave van Jezus' leven en laatste dagen ging de auteur - stellig niet de historische Judas - ervan uit dat zijn lezers de verhalen van de andere evangeliën al kenden. Het was echter zijn bedoeling daar een geheel andere, geheime versie tegenover te stellen. Met de verkeerde God die Jezus' twaalf leerlingen vereerden is de God bedoeld in wie de kerk van die tijd geloofde, evenals de joden. 


\section{Roukema}

\section{Gnostiek}

Aan de vijf 'geheime' vroegchristelijke geschriften die ik heb behandeld zouden nog tal van andere werken kunnen worden toegevoegd, die weliswaar niet expliciet een term als 'apocrief' of 'verborgen' in het opschrift of onderschrift hebben staan, maar die dezelfde geest ademen. Dat zulke geschriften veelal gnostisch worden genoemd, is een moderne aanduiding, al werd die term in de late oudheid door enkele groepen wel gebruikt. ${ }^{20} \mathrm{Met}$ 'gnostisch' bedoelt men doorgaans de visie dat de mens verlost wordt door de kennis (gnôsis) dat ieder mens in principe een goddelijk deeltje in zichzelf heeft dat uit de bovenhemelse sfeer afkomstig is en ertoe bestemd is daarnaar terug te keren. Voorts dient men in te zien dat deze wereld is geschapen door een lagere godheid en zijn machten, van wie ook het vergankelijke menselijk lichaam afkomstig is. Gnostici die zich oriënteren op Jezus Christus als Verlosser menen dat hij stamt van de ware Vader in de bovenhemelse sfeer, en dat hij op aarde aan zijn leerlingen, of aan enkelen van hen, de kennis heeft geopenbaard die nodig is om van de materiële wereld verlost te worden en na de dood van het lichaam naar de Vader op te stijgen. Zulke gnostici meenden dat dit inzicht in de hoofdstroom van het christendom - de 'kerk' - onbekend was. Om hun eigen inzichten onder groepsgenoten en belangstellenden te delen schreven of redigeerden gnostische leraren geschriften zoals die welke hierboven kort zijn geïntroduceerd. Sommige hiervan zijn ook bekend geworden bij christenen van de hoofdstroom, en in de regel wezen zij die integraal af. Soms werden losse spreuken van Jezus die in het Evangelie van Thomas stonden echter wel geciteerd als van Jezus afkomstig. Sommigen betwijfelen trouwens of dit Evangelie een gnostische boodschap (in de bovengenoemde betekenis) bevat; ${ }^{21}$ de zinspelingen daarop zijn inderdaad niet in alle opzichten volkomen duidelijk.

Overigens zijn er behalve de gnostische apocriefe geschriften nog tientallen andere vroegchristelijke evangeliën, handelingen van apostelen, brieven en openbaringen die geen duidelijk gnostisch karakter hebben en door hun auteurs ook niet 'verborgen' of 'geheim' werden genoemd, maar die door de latere kerk als 'apocrief' werden aangeduid. Dat betekende dat ze door bisschoppen niet als gezaghebbend werden beschouwd en niet in de kerk mochten worden gelezen. Dat kerkelijke gelovigen hiervoor toch belangstelling hadden, is een andere zaak. Een voorbeeld hiervan is het Protevangelie van Jacobus, dat handelt over de geboorte van Maria en van Jezus. ${ }^{22}$ 


\section{Evaluatie}

De vraag is nu hoe de gnostische 'verborgen' werken zich verhouden tot de geschriften die destijds wel door de kerk werden geaccepteerd. Zou het zo kunnen zijn dat de gnostisch-apocriefe geschriften oude tradities bevatten die historisch gezien een beter beeld van Jezus en zijn eerste leerlingen geven dan de evangeliën en de Handelingen der apostelen en brieven die in de kerk gezag kregen? Deze vraag wordt wel eens bevestigend beantwoord. In Nederland heeft bijvoorbeeld de historicus Jacob Slavenburg deze opvatting in allerlei sterk aanvechtbare publicaties verdedigd. Zo schrijft hij dat 'het christendom in zijn zuiverste essentie puur gnostisch [is]. Jezus bracht de onvervalste gnosis aan zijn leerlingen. Dat is duidelijk op te maken uit de wonderlijke geschriften die uit de kruik [met de boeken van Nag Hammadi] tevoorschijn kwamen.' Slavenburg noemt dan onder meer het Evangelie van Thomas en het Geheime boek van Jacobus. ${ }^{23}$ Daarmee correspondeert dat hij en zijn collega Willem Glaudemans alle Nag Hammadi geschriften 'in de eerste twee eeuwen van onze jaartelling' dateren. ${ }^{24}$ Als deze dateringen juist zouden zijn, dan zouden veel van de 'geheime' gnostische overleveringen over Jezus even oud zijn als de tradities in de nieuwtestamentische evangeliën, en zouden zij eventueel aanspraak kunnen maken op een gelijke of grotere historische betrouwbaarheid. Een boek dat internationaal sterk aan de verspreiding van deze visie heeft bijgedragen, is de roman van Dan Brown, The Da Vinci Code, van 2003. Brown laat daarin het fictieve karakter Sir Leigh Teabing allerlei kennis over deze materie debiteren die door veel argeloze lezers als de historische waarheid is opgevat. Zo zegt Teabing bijvoorbeeld over de geschriften van Nag Hammadi: 'these documents speak of Christ's ministry in very human term ${ }^{25}$ - terwijl het tegendeel waar is, want Christus wordt er als een goddelijke gestalte geïntroduceerd die weinig op heeft met het gewone menselijke leven. Zelfs in het Evangelie van Thomas is hij een talking head en bekommert hij zich nooit om lichamelijk zieke en gekwelde mensen, zoals in de bijbelse evangeliën. Ook noemt Teabing de Nag Hammadi geschriften en de rollen van de Dode Zee 'The earliest Christian records, ${ }^{26}$ hetgeen wetenschappelijk gezien onzin is.

Gangbaarder en naar veler inzicht meer verantwoord is het echter de meeste geschriften van het Nieuwe Testament in de laatste vier decennia van de eerste eeuw te dateren en de meeste geheime gnostische geschriften in de tweede en derde eeuw. ${ }^{27}$ Wel is het aannemelijk dat de vroegste vormen van christelijke gnostiek reeds omstreeks het jaar 100 zijn ontstaan. ${ }^{28}$ Ook 


\section{Roukema}

is het goed mogelijk dat enkele spreuken uit het Evangelie van Thomas een oude versie weergeven die in een meer uitgewerkte, dus secundaire vorm in de nieuwtestamentische evangeliën staat, en dat andere spreuken die niet in de nieuwtestamentische evangeliën staan, wel van Jezus afkomstig zijn. Een voorbeeld hiervan is spreuk 98 in het Evangelie van Thomas:

Jezus zei: Het koninkrijk van de Vader lijkt op een man die een machthebber wil doden. Thuis trok hij zijn zwaard en stak het in de muur, om te weten of zijn hand sterk genoeg was. Toen vermoordde hij de machthebber. ${ }^{29}$

In het algemeen wordt echter door historici en nieuwtestamentici erkend dat de meest betrouwbare bronnen over Jezus en het vroegste christendom te vinden zijn in het Nieuwe Testament, omdat die geschriften ouder zijn en omdat ze een breder scala van Jezus' uitspraken, gesprekken en daden beschrijven dan de 'geheime' geschriften. In de nieuwtestamentische evangeliën wordt wel eens verwezen naar 'geheim' onderricht van Jezus, maar het zou onverantwoord zijn zulke verwijzingen in te kleuren met de latere geheim genoemde geschriften; de inhoud van dat 'geheime' onderricht van Jezus is eenvoudigweg elders in de Bijbelse evangeliën te vinden. ${ }^{30}$

Vanzelfsprekend dienen de nieuwtestamentische evangeliën echter kritisch te worden bestudeerd, want niet alles wat daarin staat is echt zo gebeurd en gezegd. In veel gevallen is het meer legendarische, later ontstane materiaal te herkennen dankzij kritische vergelijking van de onderling afwijkende versies. Die analyse is een vak apart. ${ }^{31}$

Latere, als 'geheim' gepresenteerde geschriften kunnen enkele oude tradities bevatten, maar niet meer dan dat. Wel geven die andere, 'verborgen' werken een fascinerend getuigenis van de heel verschillende stromingen waarin het christendom al vroeg is uitgewaaierd.

\section{Noten}

1. Sources Chrétiennes: Christelijke Bronnen. Série annexe de textes non chrétiens: nevenserie van niet-christelijke teksten. Zie Ptolémée, Lettre à Flora: analyse, texte critique, traduction, commentaire et index grec ed. \& trans. Gilles Quispel. Sources Chrétiennes 24bis (Paris: Cerf, 1966).

2. Zie hiervoor onder meer Riemer Roukema, "La tradition apostolique et le canon 


\section{Geheime geschriften in het vroege christendom}

du Nouveau Testament," in The Apostolic Age in Patristic Thought, ed. A. Hilhorst (Leiden: Brill, 2004), 86, 103.

3. Zie voor een van de overgeleverde versies van deze 'regel van het geloof' (regula fidei) Riemer Roukema, Jezus, de gnosis en het dogma (Zoetermeer: Meinema, 2007), 227-228. Later is deze 'regel' vastgelegd in de 'Apostolische Geloofsbelijdenis' (https://www.protestantsekerk.nl/data/import/889df9bf21ac44437bee298296ef3212. pdf; geraadpleegd 26 januari 2019).

4. Zie bijv. Lee Martin McDonald, "Lists and catalogues of New Testament collections," in The canon debate, 2nd edition, ed. Lee Martin McDonald, James A. Sanders (Peabody, Mass.: Hendrickson, 2004), 591-597.

5. Een goede Engelse vertaling van de collectie van Nag Hammadi en van diverse andere gnostische werken is getiteld The Nag Hammadi Scriptures, ed. Marvin Meyer (New York: HarperCollins, 2007). Van diverse vroeg-gnostische geschriften zijn her en der Nederlandse vertalingen gepubliceerd (zie volgende voetnoten), maar een verantwoorde Nederlandse vertaling van alle bekende vroeg-gnostische werken in één band bestaat niet. De uitgave De Nag Hammadi-geschriften: een integrale vertaling van alle teksten uit de Nag Hammadi Codices en de Berlijnse Codex, volledig herziene en geactualiseerde editie, trans. Jacob Slavenburg, Willem Glaudemans (Deventer: Ankh-Hermes, 2004) is gemaakt op grond van bestaande moderne vertalingen en niet uit het Koptisch. Ondanks de assistentie van een koptologe zijn hierbij veel fouten gemaakt. Zie mijn recensie: Riemer Roukema, "Alternatief vroeg christendom," in Centraal Weekblad, 14 januari 2005, 11, ook op https://www.riemerroukema.nl/ downloads/RiemerRoukema-0209.pdf.

6. Nederlandse vertalingen onder meer in: Het evangelie van Thomas: ingeleid en vertaald, met de Koptische en Griekse teksten, ed. \& trans. Riemer Roukema (Zoetermeer: Meinema, 2005); Gerard Luttikhuizen, De evangeliën van Thomas, Maria Magdalena en Judas: ingeleid, vertaald en toegelicht (Almere: Parthenon, 2018), 42-72. In het Nieuwe Testament komt Thomas onder meer voor in Matteüs 10:3; Johannes 11:16; 14:5; 20:24-28; 21:2; Handelingen 1:13.

7. Bijv. Plato, Phaedrus 249C-250C; Symposium 189E-193E.

8. Zie over haar Lucas 8:2; Matteüs 27:56, 61; 28:1; Johannes 20:1-18; Evangelie van Maria.

9. Luttikhuizen, De evangeliën van Thomas, Maria Magdalena en Judas, 101.

10. Ingeleid door John D. Turner, vertaald door Marvin Meyer, "The Book of Thomas," in The Nag Hammadi Scriptures, ed. Meyer, 235-245. Een andere inleiding in Birger A. Pearson, Ancient Gnosticism: traditions and literature (Minneapolis: Fortress, 2007), 268-272. Met Mathaias zal Jezus' leerling Matthaios ofwel Matteüs bedoeld zijn; zie voor hem Matteüs 9:9; 10:3.

11. Vgl. Johannes $12: 31 ; 14: 30 ; 16: 11$.

12. Ingeleid door Madeleine Scopello, vertaald door Marvin Meyer, "The Secret Book of James," in The Nag Hammadi Scriptures, ed. Meyer, 19-30. Zie ook Pearson, Ancient Gnosticism, 218-221.

13. Matteüs 13:55; Galaten 1:18-19; 2:9-12; Handelingen 15:13-21; Evangelie van Thomas 12. 


\section{Roukema}

14. Ingeleid en vertaald door Roelof van den Broek, Gnosis in de oudheid: Nag Hammadi in context (Amsterdam: In de Pelikaan, 2010), 247-303. Zie ook Gerard P. Luttikhuizen, Gnostic Revisions of Genesis Stories and Early Jesus Traditions (Leiden: Brill, 2006), 1-116.

15. Voor deze Johannes zie bijv. Matteüs 4:21; 10:2; 17:1; Marcus 13:3.

16. Van den Broek, Gnosis in de oudheid, 267.

17. Ingeleid, vertaald en toegelicht door Luttikhuizen, De evangeliën van Thomas, Maria Magdalena en Judas, 131-199. Zie ook Jacques van der Vliet, Het Evangelie van Judas: verrader of bevrijder? (Utrecht: Servire, 2006).

18. Vertaling Luttikhuizen.

19. Matteüs 10:4; 26:47-56; 27:1-10; Johannes 6:70-71; 13:2, 18-30; 18:1-3; Handelingen 1:15-20.

20. Uitgebreider over de gnostiek: Riemer Roukema, Gnosis en geloof in het vroege christendom: een inleiding tot de gnostiek, 2de druk (Zoetermeer: Meinema, 2004); G.P. Luttikhuizen, De veelvormigheid van het vroegste christendom (Eindhoven: Damon, 2005); Van den Broek, Gnosis in de oudheid.

21. Zo bijv. Luttikhuizen, De evangeliën van Thomas, Maria Magdalena en Judas, 39.

22. Zie hiervoor de collecties De apocriefen van het Nieuwe Testament: buitenbijbelse evangeliën, handelingen, brieven en openbaringen, trans. A.F.J. Klijn (Kampen: Ten Have, 2006); The apocryphal New Testament: a collection of apocryphal Christian literature in an English translation, trans. J.K. Elliott (Oxford: Clarendon, 1993); New Testament apocrypha: more noncanonical scriptures, Vol. I, ed. Tony Burke, Brent Landau (Grand Rapids, Mich.: Eerdmans, 2016).

23. Jacob Slavenburg, Een ander testament: Onbekende geschriften over het leven van Jezus en zijn geheime leringen (Deventer: Ankh-Hermes, 1991), 69. Dezelfde tendens in idem, Valsheid in geschrifte: de verborgen agenda van bijbelschrijvers (Zutphen: Walburg Pers, 2005), 59-166; De Nag Hammadi-geschriften, trans. Slavenburg, Glaudemans, 39; soortgelijk ook Fenny Kruize, Goddelijke vrijheid: een heilzame weg (Deventer: Ankh-Hermes, 2008), 76.

24. De Nag Hammadi-geschriften, trans. Slavenburg, Glaudemans, 19.

25. Dan Brown, The Da Vinci Code (London: Corgi Books, 2004), 317.

26. Brown, The Da Vinci Code, 331.

27. Zie bijv. de seculiere nieuwtestamenticus Bart D. Ehrman, The New Testament: a historical introduction to the early Christian writings (New York, Oxford: Oxford University Press, 2008), 90, 119, 139, 183, waar hij de nieuwtestamentische evangeliën dateert tussen 65 en 95, hetgeen breed wordt gedeeld. Voor de in dit artikel behandelde 'geheime' geschriften zie Pearson, Ancient Gnosticism; het Evangelie van Thomas dateert hij omstreeks 140 (p. 267); het Boek van Thomas omstreeks 200 (p. 272); het Geheime boek van Jacobus tusen 150 en 200 (p. 221); geschriften zoals het Geheime boek van Johannes in de tweede eeuw (p. 132; zijn hypothese van een oudere joodse, niet-christelijke oorsprong zou ik echter niet beamen); het Evangelie van Judas omstreeks 150 (p. 97).

28. Voor oude tradities over Simon de Tovenaar en Satornilus zie Roukema, Gnosis en geloof in het vroege christendom, 24-34; 45-49; Pearson, Ancient Gnosticism, 26-33; 


\section{Geheime geschriften in het vroege christendom}

34-35.

29. Vertaling Roukema. Vgl. ook Luttikhuizen, De veelvormigheid van het vroegste Christendom, 55-56.

30. Bijv. Marcus 4:10-11; zie Riemer Roukema, Jezus, de gnosis en het dogma (Zoetermeer: Meinema, 2007), 178-193.

31. Zie bijv. Ian Boxall, SCM studyguide to New Testament interpretation (Norwich: SCM, 2007); The Blackwell companion to the New Testament, ed. David E. Aune (Chichester: Blackwell, 2010). 